Research Paper

\title{
Defining Radiation-Induced Hepatic Toxicity in Hepatocellular Carcinoma Patients Treated with Stereotactic Body Radiotherapy
}

\author{
Jin Ho Song ${ }^{1,5^{*}}$, Bae-Kwon Jeong $2,5^{*}$, Hoon-Sik Choi ${ }^{1}$, Hojin Jeong 2,5 , Yun Hee Lee ${ }^{2,5}$, Hong Jun Kim ${ }^{3,5}$, Tae \\ Hyo Kim ${ }^{3,5}$, Woon Tae Jung 3,5 , Ok Jae Lee ${ }^{3,5}$, Hong Seok Jang, , Byung Ock Choi ${ }^{4}$ and Ki Mun Kang ${ }^{2,5} \bowtie$ \\ 1. Department of Radiation Oncology, Gyeongsang National University School of Medicine and Gyeongsang National University Changwon Hospital, 51472 \\ Changwon, Korea \\ 2. Department of Radiation Oncology, Gyeongsang National University School of Medicine and Gyeongsang National University Hospital, 52727 Jinju, Korea \\ 3. Department of Internal Medicine, Gyeongsang National University School of Medicine and Gyeongsang National University Hospital, 52727 Jinju, Korea \\ 4. Department of Radiation Oncology, Seoul St. Mary's Hospital, College of Medicine, The Catholic University of Korea, 06591 Seoul, Korea \\ 5. Institute of Health Sciences, Gyeongsang National University, 52727 Jinju, Korea \\ *JHS and BKJ contributed equally to this work
}

$\triangle$ Corresponding author: Professor Ki Mun Kang; Mailing address: Department of Radiation Oncology, Gyeongsang National University School of Medicine, 79 Gangnam-ro, Jinju 52727, Korea. E-mail: jsk92@gnu.ac.kr; Tel: +82-55-750-9200; Fax: +82-55-750-9229

(c) Ivyspring International Publisher. This is an open access article distributed under the terms of the Creative Commons Attribution (CC BY-NC) license (https:// creativecommons.org/licenses/by-nc/4.0/). See http://ivyspring.com/terms for full terms and conditions.

Received: 2017.06.21; Accepted: 2017.08.28; Published: 2017.11.12

\begin{abstract}
The definition and criteria of radiation-induced hepatic toxicity (RIHT) in hepatocellular carcinoma patients vary among studies. Therefore, the reported rates of RIHT differ among studies, and this causes confusion. In this study, we evaluated RIHT using several laboratory and clinical parameters, and analyzed which criterion is more correlated with RT and survival. Forty-five HCC patients treated with stereotactic body radiotherapy were included for the analysis. All patients had unresectable $\mathrm{HCC}$ and Child-Pugh (CP) class A or B baseline liver function. A median total dose of $45 \mathrm{~Gy}$ was delivered by CyberKnife in 3 fractions. For individual laboratory parameter, $\geq$ grade 2 toxicity development of bilirubin, albumin, or prothrombin time by Common Terminology Criteria of Adverse Effects (CTCAE) was correlated with mean liver dose and survival. However, serum transaminases had no correlation with liver mean dose and survival, and were rather affected by other local treatments. Compared to the CTCAE, the increase in the CP score of 2 points or more was better correlated with liver failure and overall survival, and it was not affected by other local treatments or tumor progression. We concluded RIHT was better defined by the change in the CP score rather than the CTCAE in patients treated by stereotactic body radiotherapy for HCC.
\end{abstract}

Key words: Hepatocellular carcinoma, radiation therapy, stereotactic body radiotherapy, radiation-induced liver disease, Child-Pugh score

\section{Introduction}

Hepatocellular carcinoma (HCC) is still the second leading cause of cancer death in South Korea despite of the advancement in treatment modalities [1, 2]. Traditionally, radiation therapy (RT) had a limited role for the treatment of HCC because of the low tolerability of the liver to radiation. However, with the advancement in RT techniques, several reports showed promising results regarding the role of RT in HCC treatment, and recently some guidelines have recommended RT as a treatment option [2-4]. However, in spite of modern RT techniques, radiation-induced hepatic toxicity (RIHT) is still the most common concern while irradiating the liver, especially in HCC patients with poor liver function.

Classic radiation-induced liver disease (RILD) is a traditionally accepted concept of hepatic toxicity, which is characterized pathologically by complete obliteration of central veins of hepatic lobules, and 
clinically by anicteric hepatomegaly, ascites, and isolated elevation of alkaline phosphatase $[5,6]$. It is usually observed in patients who have fairly well-functioning livers, and when the whole liver is irradiated with doses of 30-35 Gy.

However, the classic type of RILD is not the dominant type of hepatic toxicity in HCC patients these days. This is because HCC patients have decreased liver function due to the underlying liver cirrhosis or chronic hepatic disease, and nowadays only partial volume of the liver is usually irradiated with a high dose $[5,6]$. Therefore, to describe this non-classic type RILD, several different criteria were adopted, such as the Common Terminology Criteria for Adverse Events (CTCAE), or the change of the Child-Pugh (CP) score [7-13]. However, since the definition of non-classic RILD is not clear and the clinical significance of these criteria has not been reported, several criteria and different reporting methods are used in studies [7-13]. In addition, since other local therapies such as trans-arterial chemoembolization (TACE) are commonly combined with RT [14, 15], and intrahepatic tumor progression is commonly noted, the criteria can be affected by these confounding factors and may over-estimate or under-estimate RIHT.

In this study, we evaluated hepatic toxicity using several laboratory and clinical parameters, and analyzed which criterion is more correlated with radiation and survival. All patients were diagnosed as having primary HCC with underlying chronic liver disease, and were treated with stereotactic body radiotherapy (SBRT), which is representative of high-dose partial liver radiation.

\section{Methods}

\section{Patient selection}

The inclusion criteria for this study were as follows: 1) unresectable HCC; 2) baseline CP class A or B; 3) Eastern Cooperative Oncology Group (ECOG) performance status 0 or $1 ; 4)$ hepatic function laboratory findings available at baseline and within 3 months after SBRT; 5) no previous history of radiation therapy for the liver.

From February 2010 to September 2015, 45 patients were treated with SBRT at Gyeongsang National University Hospital and they fulfilled the inclusion criteria. The medical records and treatment plans were retrospectively reviewed to analyze hepatic toxicity and treatment outcome. This study was approved by the institutional review board (IRB) of the Gyeongsang National University Hospital (IRB No. 2016-03-002).

\section{Radiation treatment}

SBRT was performed using the Cyberknife (Accuray Inc., Sunnyvale CA, USA), which is a frameless robotic system that delivers 6-MV photons without a flattening filter. An orthogonal x-ray image-guided system is incorporated which allows near real-time tumor tracking.

One week before simulation, three fiducial gold seeds were inserted in the liver parenchyma near the tumor targets, which act as radiographic landmarks for image guidance. Computed tomography (CT) simulation was performed in the supine position with an immobilization device, and spiral 4-dimensional (4D) CT images with $1.5 \mathrm{~mm}$ slice thickness were acquired. The gross tumor volume (GTV) was defined as the contrast-enhanced tumor on CT scans. MRI images were fused with the CT scan images. The clinical target volume was same as GTV, and a $5 \mathrm{~mm}$ margin was added symmetrically to create the PTV. The PTV was modified if the bowel is included or in proximity to the target. Four-dimensional treatment plans were generated to consider the tumor motion and deformation on the basis of $4 \mathrm{D}-\mathrm{CT}$.

A median total dose of 45 Gy (range, 33-45 Gy) was prescribed to the median $79 \%$ (range, 74-95\%) isodose level, which encompassed $95 \%$ of the PTV. The dose was delivered in median 3 fractions (range, 3-4 fractions) every other day. The normal tissue dose constraints were as follow: 1) the normal liver volume receiving < 17 Gy should be at least $700 \mathrm{cc}, 2)$ the maximum point dose to spinal cord should be below $18 \mathrm{~Gy}$, and 3) maximum dose delivered to $1 \mathrm{cc}$ of small bowel should be below $12 \mathrm{~Gy}$.

\section{Evaluation of hepatic toxicity}

During the SBRT treatment, patients were seen by the physician every treatment day, and after the completion of SBRT, all patients were followed up every 1 to 3 months. Physical examination and blood tests were performed at every visit to assess hepatic toxicity.

The following parameters related to liver function were included: 1) aspartate transaminase (AST), 2) alanine transaminase (ALT), 3) alkaline phosphatase (ALP), 4) total bilirubin (BIL), 5) albumin (ALB), and 6) international normalized ratio (INR) for the prothrombin time. Based on these laboratory findings, hepatic toxicity was graded based on the CTCAE version 4.0 [16]. The presence of ascites or hepatic encephalopathy was also assessed by physical examination or imaging findings, and the $\mathrm{CP}$ score were recorded at every visit [17]. The definition of CTCAE version 4.0 and CP score is shown in Table 1. For individual parameters, grade 2 or higher toxicity according to the CTCAE was considered abnormal. 
Table 1. The Common Terminology Criteria for Adverse Events (CTCAE) version 4.0 and Child-Pugh (CP) criteria for hepatic function.

\begin{tabular}{llll}
\hline CTCAE criteria & Grade 1 & Grade 2 & Grade 3 \\
\hline AST & $1.0 \sim 3.0 \times$ ULN & $3.0 \sim 5.0 \times$ ULN & $5.0 \sim 20.0 \times$ ULN \\
ALT & $1.0 \sim 3.0 \times$ ULN & $3.0 \sim 5.0 \times$ ULN & $5.0 \sim 20.0 \times$ ULN \\
Alkaline phosphatase & $1.0 \sim 2.5 \times$ ULN & $2.5 \sim 5.0 \times$ ULN & $5.0 \sim 20.0 \times$ ULN \\
Bilirubin & $1.0 \sim 1.5 \times$ ULN & $1.5 \sim 3.0 \times$ ULN & $3.0 \sim 10.0 \times$ ULN \\
Albumin & $3 \sim$ LLN g/dL & $2 \sim 3 \mathrm{~g} / \mathrm{dL}$ & $<2 \mathrm{~g} / \mathrm{dL}$ \\
INR & $1.0 \sim 1.5 \times$ ULN & $1.5 \sim 2.5 \times$ ULN & $>2.5 \times$ ULN \\
Ascites & Asymptomatic; & Symptomatic; & Severe symptoms; \\
& No intervention & Medical intervention & invasive intervention \\
\hline CP criteria & $\mathbf{1}$ point & $\mathbf{2}$ points & $\mathbf{3}$ points \\
\hline Bilirubin & $<2 \mathrm{mg} / \mathrm{dL}$ & $2 \sim 3 \mathrm{mg} / \mathrm{dL}$ & $>3$ mg/dL \\
Albumin & $>3.5 \mathrm{~g} / \mathrm{dL}$ & $2.8 \sim 3.5 \mathrm{~g} / \mathrm{dL}$ & $<.0 \times$ LLN \\
INR & $<1.7$ & $1.7 \sim 2.2$ & $>2.8$ g/dL \\
Ascites & No & Controlled & $>2.2$ \\
Encephalopathy & No & Controlled & Poorly controlled \\
\hline
\end{tabular}

\section{Statistical analysis}

For this study, we hypothesized that the best criterion for RIHT should not be influenced by any other local treatment or intrahepatic tumor progression, but it should be correlated with radiation dose to the liver and the development of liver failure, and eventually it should reflect overall survival. Therefore, each parameter and criterion was analyzed with respect to whether it has any association with other local treatments, intrahepatic tumor progression, and the mean liver dose. Fisher's exact test and the independent t-test were used for this analysis. For survival analysis, Kaplan-Meier method was used, and to determine the difference between groups, the log-rank test was used. All statistical analyses were performed using SPSS version 21.0 (SPSS Institute, Chicago, IL) and a $P$ value of $<0.05$ was considered to be statistically significant.

\section{Results}

\section{Patient characteristics}

The patient characteristics are shown in Table 2. Thirty-six $(80.0 \%)$ patients were male, and the median age was 63 years (range, 41-78 years). All patients had underlying chronic hepatitis which was caused by hepatitis B virus $(51.1 \%)$, hepatitis C virus $(17.8 \%)$, alcohol $(17.8 \%)$, or mixed etiology $(13.3 \%)$. Liver cirrhosis was observed in $40(88.9 \%)$ patients. The CP score before RT was 5 points in 23 (51.1\%) patients, and 6 points in $14(48.9 \%)$ patients. There were 8 $(17.8 \%)$ patients with $\mathrm{CP}$ class $\mathrm{B}$ before the initiation of RT.

Portal vein tumor thrombosis was present in 22 (48.9\%) patients, and the tumor stage was III-IV in 34 $(75.6 \%)$ patients according to the modified Union for International Cancer Control (UICC) staging system, and the tumor stage was III-IV in $27(60.0 \%)$ patients according to the American Joint Committee on Cancer
(AJCC) system. The median GTV was $27.5 \mathrm{cc}$ (range, 1.5-718.3 cc), and the mean liver dose was median 12.7 Gy (range, 0.3-30.9 Gy).

Table 2. Patient characteristics

\begin{tabular}{|c|c|c|}
\hline Variables & $\mathbf{n}$ & $(\%)$ \\
\hline Age (years) & \multicolumn{2}{|c|}{ median 63 (range, 41-78) } \\
\hline \multicolumn{3}{|l|}{ Gender } \\
\hline Male & 36 & 80.0 \\
\hline Female & 9 & 20.0 \\
\hline \multicolumn{3}{|l|}{ ECOG PS } \\
\hline 0 & 16 & 35.6 \\
\hline 1 & 29 & 64.4 \\
\hline \multicolumn{3}{|c|}{ Liver cirrhosis } \\
\hline No & 5 & 11.1 \\
\hline Yes & 40 & 88.9 \\
\hline \multicolumn{3}{|l|}{ Etiology } \\
\hline HBV & 23 & 51.1 \\
\hline $\mathrm{HCV}$ & 8 & 17.8 \\
\hline Alcohol & 8 & 17.8 \\
\hline Mixed & 6 & 13.3 \\
\hline \multicolumn{3}{|c|}{ Child-Pugh class before RT } \\
\hline $\mathrm{A}(5)$ & 23 & 51.1 \\
\hline$A(6)$ & 14 & 48.9 \\
\hline B (7-9) & 8 & 17.8 \\
\hline \multicolumn{3}{|c|}{ mUICC tumor stage } \\
\hline I-II & 11 & 24.4 \\
\hline III-IV & 34 & 75.6 \\
\hline \multicolumn{3}{|c|}{ AJCC tumor stage } \\
\hline I-II & 18 & 40.0 \\
\hline III-IV & 27 & 60.0 \\
\hline \multicolumn{3}{|c|}{ Portal vein tumor thrombosis } \\
\hline No & 23 & 51.1 \\
\hline Yes & 22 & 48.9 \\
\hline \multicolumn{3}{|c|}{ Previous treatment } \\
\hline None & 10 & 22.2 \\
\hline TACE & 33 & 73.3 \\
\hline RFA & 11 & 25.5 \\
\hline Surgery & 12 & 26.7 \\
\hline
\end{tabular}

Ten $(22.2 \%)$ patients received SBRT as the initial HCC treatment, however, $35(77.8 \%)$ had previously received other local treatments such as surgery $(26.7 \%)$, TACE $(73.3 \%)$, and RFA (25.5\%). TACE was performed median 3 times (range, 1-10 times), and RFA was performed median one time (range, 1-3 
times) before RT. Twenty-seven (60.0\%) patients received these local treatments within 3 months before SBRT. After SBRT, twelve (26.7\%) patients received TACE within 3 months. Four $(8.9 \%)$ patients received TACE two times, and the other eight (17.8\%) patients received TACE once. Other local therapies were not performed within 3 months after SBRT. However, intrahepatic tumor progression was observed in 11 (25.5\%) patients within 3 months after SBRT. At the last follow-up at median 10.3 months (range, 0.7-62.4 months) after the completion of SBRT, nine $(20.0 \%)$ patients had liver failure due to any cause.

\section{Significance of individual parameters}

Table 3 shows the significance of individual laboratory parameters. The AST and ALT levels were abnormally increased in 13 (28.9\%) and 7 (15.6\%) patients. The elevation of AST and ALT levels was more frequently observed in patients who had received TACE within this period $(P=0.022$ and 0.047 , respectively). However, the elevation of AST and ALT levels did not show a significant correlation with the mean liver dose as well as with the development of liver failure and overall survival. The elevation of ALP level was only observed in one patient, and therefore it had no clinical significance, although this patient had received a high mean liver dose of 22.8 Gy. However, this patient did not have ascites or hepatomegaly, and other parameters such as AST and ALT were also increased. Therefore, this patient was not regarded as having the classic type of RILD. The deterioration of the ALP level in this patient was considered to be due to intrahepatic tumor progression.

Table 3. The significance of individual laboratory parameters*. Each parameter was considered abnormal when the toxicity was grade 2 or higher according to the Common Terminology Criteria for Adverse Events (CTCAE) version 4.0.

\begin{tabular}{|c|c|c|c|c|c|c|c|c|c|c|}
\hline Individual parameters & $\begin{array}{l}\text { Other local } \\
\text { treatment }(n=12)\end{array}$ & $P$ & $\begin{array}{l}\text { Tumor } \\
\text { progression } \\
(\mathrm{n}=11)\end{array}$ & $P$ & $\begin{array}{l}\text { Mean liver } \\
\text { dose (Gy) }\end{array}$ & $P$ & $\begin{array}{l}\text { Liver failure } \\
(\mathrm{n}=9)\end{array}$ & $P$ & $\begin{array}{l}1 \text {-year overall } \\
\text { survival (\%) }\end{array}$ & $P$ \\
\hline AST Grade 0-1 (32) & $\begin{array}{l}5 / 32 \\
(15.6 \%)\end{array}$ & 0.022 & $\begin{array}{l}7 / 32 \\
(21.9 \%)\end{array}$ & 0.704 & $13.5 \pm 6.9$ & 0.402 & $\begin{array}{l}5 / 32 \\
(15.6 \%)\end{array}$ & 0.411 & $76.6 \%$ & 0.219 \\
\hline$\geq$ Grade 2 (13) & $\begin{array}{l}7 / 13 \\
(53.8 \%)\end{array}$ & & $\begin{array}{l}4 / 13 \\
(30.8 \%)\end{array}$ & & $15.2 \pm 3.4$ & & $\begin{array}{l}4 / 13 \\
(30.8 \%)\end{array}$ & & $67.9 \%$ & \\
\hline ALT Grade 0-1 (38) & $\begin{array}{l}8 / 38 \\
(21.1 \%)\end{array}$ & 0.047 & $\begin{array}{l}9 / 38 \\
(23.7 \%)\end{array}$ & $>0.999$ & $13.6 \pm 6.4$ & 0.320 & $\begin{array}{l}8 / 38 \\
(21.1 \%)\end{array}$ & $>0.999$ & $74.8 \%$ & 0.417 \\
\hline$\geq$ Grade $2(7)$ & $\begin{array}{l}4 / 7 \\
(57.1 \%)\end{array}$ & & $\begin{array}{l}2 / 7 \\
(28.6 \%)\end{array}$ & & $16.1 \pm 3.2$ & & $\begin{array}{l}1 / 7 \\
(14.3 \%)\end{array}$ & & $50.0 \%$ & \\
\hline ALP Grade 0-1 (44) & $\begin{array}{l}11 / 44 \\
(25.0 \%)\end{array}$ & 0.267 & $\begin{array}{l}11 / 44 \\
(25.0 \%)\end{array}$ & $>0.999$ & $13.8 \pm 6.0$ & 0.146 & $\begin{array}{l}9 / 44 \\
(20.5 \%)\end{array}$ & $>0.999$ & $76.8 \%$ & 0.117 \\
\hline$\geq$ Grade $2(1)$ & $\begin{array}{l}1 / 1 \\
(100.0 \%)\end{array}$ & & $\begin{array}{l}0 / 1 \\
(0.0 \%)\end{array}$ & & 22.8 & & $\begin{array}{l}0 / 1 \\
(0.0 \%\end{array}$ & & $0.0 \%$ & \\
\hline BIL Grade 0-1 (26) & $\begin{array}{l}9 / 26 \\
(34.6 \%)\end{array}$ & 0.191 & $\begin{array}{l}6 / 26 \\
(23.1 \%)\end{array}$ & 0.803 & $13.4 \pm 6.2$ & 0.472 & $\begin{array}{l}3 / 26 \\
(11.5 \%)\end{array}$ & 0.137 & $84.3 \%$ & 0.018 \\
\hline$\geq$ Grade 2 (19) & $\begin{array}{l}3 / 19 \\
(15.8 \%)\end{array}$ & & $\begin{array}{l}5 / 19 \\
(26.3 \%)\end{array}$ & & $14.7 \pm 6.0$ & & $\begin{array}{l}6 / 19 \\
(31.6 \%)\end{array}$ & & $59.1 \%$ & \\
\hline ALB Grade 0-1 (32) & $\begin{array}{l}9 / 32 \\
(28.1 \%)\end{array}$ & $>0.999$ & $\begin{array}{l}7 / 32 \\
(21.9 \%)\end{array}$ & 0.704 & $12.7 \pm 4.6$ & 0.078 & $\begin{array}{l}2 / 32 \\
(6.3 \%)\end{array}$ & 0.001 & $83.5 \%$ & $<0.001$ \\
\hline > Grade 2 (13) & $\begin{array}{l}3 / 13 \\
(28.9 \%)\end{array}$ & & $\begin{array}{l}4 / 13 \\
(30.8 \%)\end{array}$ & & $17.2 \pm 8.1$ & & $\begin{array}{l}7 / 13 \\
(53.8 \%)\end{array}$ & & $41.7 \%$ & \\
\hline INR Grade 0-1 (39) & $\begin{array}{l}10 / 39 \\
(25.6 \%)\end{array}$ & 0.650 & $\begin{array}{l}10 / 39 \\
(25.6 \%)\end{array}$ & $>0.999$ & $13.5 \pm 5.6$ & 0.361 & $\begin{array}{l}4 / 39 \\
(10.3 \%)\end{array}$ & 0.001 & $81.5 \%$ & $<0.001$ \\
\hline$\geq$ Grade 2 (6) & $\begin{array}{l}2 / 6 \\
(33.3 \%)\end{array}$ & & $\begin{array}{l}1 / 6 \\
(16.7 \%)\end{array}$ & & $17.1 \pm 8.8$ & & $\begin{array}{l}5 / 6 \\
(83.3 \%)\end{array}$ & & $25.0 \%$ & \\
\hline
\end{tabular}

*We hypothesized that the best criterion for RIHT should not be influenced by any other local treatment or intrahepatic tumor progression, but it should be correlated with radiation dose to the liver and the development of liver failure, and eventually it should reflect overall survival. 
Compared to these parameters, BIL, ALB, and INR showed significant correlations with overall survival. Patients who had more than grade 2 BIL, ALB, or INR toxicity had worse 1-year overall survival $(59.1 \%, 41.7 \%$, and $25.0 \%$, respectively) compared to patients who had grade 0 or 1 toxicity $(84.3 \%, 83.5 \%$, and $81.5 \%$, respectively) $(P=0.018$, $<0.001$, and <0.001). ALB and INR were also correlated with the development of liver failure. Seven of the $13(53.8 \%)$ patients who had decreased ALB, and five of the six (83.3\%) patients who had increased INR, developed liver failure at the last follow-up. However, none of these parameters caused statistically significant differences in the mean liver dose.

\section{Significance of the CTACE}

Table 4 shows the correlation between several criteria of RIHT and their clinical significances. Patients who experienced any CTCAE grade 2 or higher liver toxicity, received a slightly higher mean liver dose (15.6 Gy vs. 13.2 Gy, $P=0.018$ ) and a lower 1 -year overall survival rate $(67.7 \%$ vs $84.4 \%, P=$ 0.038). Although the CTCAE $\geq$ grade 2 criterion showed no statistically significant correlation with other local treatments and tumor progression, the correlation with the development liver failure was also not significant.

If RIHT was defined as any CTCAE grade 3 or higher liver toxicity, the association with radiation was decreased. This criterion was affected by other local treatments $(\mathrm{p}=0.043)$, and it showed no correlation with the mean liver dose or liver failure, although the survival difference was larger $(81.7 \%$ vs. $40.6 \%, P=0.001$ ) compared to any CTCAE grade 2 or higher liver toxicity.

\section{Significance of the CP score}

We also analyzed the correlation of clinical significance and the change in CP score with several cut-off values. As shown in Table 4, the increase in CP score of 2 points or more was the best criterion of RIHT. The increase in CP score of $\geq 2$ points was not affected by other local treatments $(25.0 \%$ vs. $27.6 \%, P$ $>0.999)$ or tumor progression $(25.0 \%$ vs. $24.1 \%, P>$ $0.999)$. The mean liver dose was statistically higher in patients with an increased CP score (17.9 Gy vs. 11.8 Gy, $P=0.005$ ). None of the patients ( 0 out of 29 patients) whose $\mathrm{CP}$ score was not increased by more than 2 points developed liver failure at the last follow-up. The 1-year overall survival was $34.0 \%$ in patients with an increased $\mathrm{CP}$ score of $\geq 2$ points compared to $94.1 \%$ in patients with an increase in $\mathrm{CP}$ score of 1 point or less (Figure $1, P<0.001$ ).

Table 4. The significance of various criteria for radiation-induced hepatic toxicity. The Common Terminology Criteria for Adverse Events (CTCAE) version 4.0 and the increase in Child-Pugh (CP) score were compared.

\begin{tabular}{|c|c|c|c|c|c|c|c|c|c|c|}
\hline Criteria of RIHT & $\begin{array}{l}\text { Other local } \\
\text { treatment } \\
(\mathrm{n}=12)\end{array}$ & $P$ & $\begin{array}{l}\text { Tumor progression } \\
(\mathrm{n}=11)\end{array}$ & $P$ & $\begin{array}{l}\text { Mean liver } \\
\text { dose (Gy) }\end{array}$ & $P$ & $\begin{array}{l}\text { Liver failure } \\
(\mathrm{n}=9)\end{array}$ & $P$ & $\begin{array}{l}\text { 1-year overall } \\
\text { survival (\%) }\end{array}$ & $P$ \\
\hline $\begin{array}{l}\text { CTCAE } \geq \text { grade } 2 \\
\text { No (17) }\end{array}$ & $4 / 17(23.5 \%)$ & $>0.999$ & $\begin{array}{l}3 / 17 \\
(17.6 \%)\end{array}$ & 0.493 & $11.2 \pm 4.3$ & 0.018 & $\begin{array}{l}1 / 17 \\
(5.9 \%)\end{array}$ & 0.122 & $84.4 \%$ & 0.038 \\
\hline Yes (28) & $8 / 28(28.6 \%)$ & & $\begin{array}{l}8 / 28 \\
(28.6 \%)\end{array}$ & & $15.6 \pm 6.5$ & & $\begin{array}{l}8 / 28 \\
(28.6 \%)\end{array}$ & & $67.7 \%$ & \\
\hline $\begin{array}{l}\text { CTCAE } \geq \text { grade } 3 \\
\text { No (36) }\end{array}$ & 7/36 (19.4\%) & 0.043 & $\begin{array}{l}7 / 36 \\
(19.4 \%)\end{array}$ & 0.190 & $13.2 \pm 5.9$ & 0.113 & $\begin{array}{l}6 / 36 \\
(16.7 \%)\end{array}$ & 0.354 & $81.7 \%$ & 0.001 \\
\hline Yes (9) & $5 / 9(55.6 \%)$ & & $\begin{array}{l}4 / 9 \\
(44.4 \%)\end{array}$ & & $16.8 \pm 6.3$ & & $\begin{array}{l}3 / 9 \\
(33.3 \%)\end{array}$ & & $40.6 \%$ & \\
\hline $\begin{array}{l}\text { CP score } \geq 1 \\
\text { point } \\
\text { No }(20)\end{array}$ & $\begin{array}{l}5 / 20 \\
(25.0 \%)\end{array}$ & $>0.999$ & $\begin{array}{l}3 / 20 \\
(15.0 \%)\end{array}$ & 0.297 & $11.4 \pm 3.9$ & 0.006 & $\begin{array}{l}0 / 20 \\
(0.0 \%)\end{array}$ & 0.002 & $92.9 \%$ & 0.002 \\
\hline Yes (25) & $\begin{array}{l}7 / 25 \\
(28.0 \%)\end{array}$ & & $\begin{array}{l}8 / 25 \\
(32.0 \%)\end{array}$ & & $16.0 \pm 6.8$ & & $\begin{array}{l}9 / 25 \\
(33.6 \%)\end{array}$ & & $53.8 \%$ & \\
\hline $\begin{array}{l}\text { CP score } \geq 2 \\
\text { points } \\
\text { No }(29)\end{array}$ & $\begin{array}{l}8 / 29 \\
(27.6 \%)\end{array}$ & $>0.999$ & $\begin{array}{l}7 / 29 \\
(24.1 \%)\end{array}$ & $>0.999$ & $11.8 \pm 4.1$ & 0.005 & $\begin{array}{l}0 / 29 \\
(0.0 \%)\end{array}$ & $<0.001$ & $94.1 \%$ & $<0.001$ \\
\hline Yes (16) & $\begin{array}{l}4 / 16 \\
(25.0 \%)\end{array}$ & & $\begin{array}{l}4 / 16 \\
(25.0 \%)\end{array}$ & & $17.9 \pm 7.2$ & & $\begin{array}{l}9 / 16 \\
(56.3 \%)\end{array}$ & & $34.0 \%$ & \\
\hline $\begin{array}{l}\text { CP score } \geq 3 \\
\text { points } \\
\text { No }(35)\end{array}$ & $\begin{array}{l}10 / 35 \\
(28.6 \%)\end{array}$ & 0.705 & $\begin{array}{l}9 / 35 \\
(25.7 \%)\end{array}$ & $>0.999$ & $12.7 \pm 4.6$ & 0.074 & $\begin{array}{l}1 / 35 \\
(2.9 \%)\end{array}$ & $<0.001$ & $87.0 \%$ & $<0.001$ \\
\hline Yes (10) & $\begin{array}{l}2 / 10 \\
(20.0 \%)\end{array}$ & & $\begin{array}{l}2 / 10 \\
(20.0 \%)\end{array}$ & & $18.3 \pm 8.5$ & & $\begin{array}{l}8 / 10 \\
(80.0 \%)\end{array}$ & & $29.2 \%$ & \\
\hline $\begin{array}{l}\text { Change in CP } \\
\text { class } \\
\text { No }(23)\end{array}$ & $\begin{array}{l}6 / 23 \\
(26.1 \%)\end{array}$ & $>0.999$ & $\begin{array}{l}4 / 23 \\
(17.4 \%)\end{array}$ & 0.314 & $11.3 \pm 4.1$ & 0.002 & $\begin{array}{l}0 / 23 \\
(0.0 \%)\end{array}$ & 0.001 & $93.3 \%$ & $<0.001$ \\
\hline Yes (22) & $\begin{array}{l}6 / 22 \\
(27.3 \%)\end{array}$ & & $\begin{array}{l}7 / 22 \\
(31.8 \%)\end{array}$ & & $16.7 \pm 6.6$ & & $\begin{array}{l}9 / 22 \\
(40.9 \%)\end{array}$ & & $46.2 \%$ & \\
\hline
\end{tabular}

*We hypothesized that the best criterion for RIHT should not be influenced by any other local treatment or intrahepatic tumor progression, but it should be correlated with radiation dose to the liver and the development of liver failure, and eventually it should reflect overall survival. 


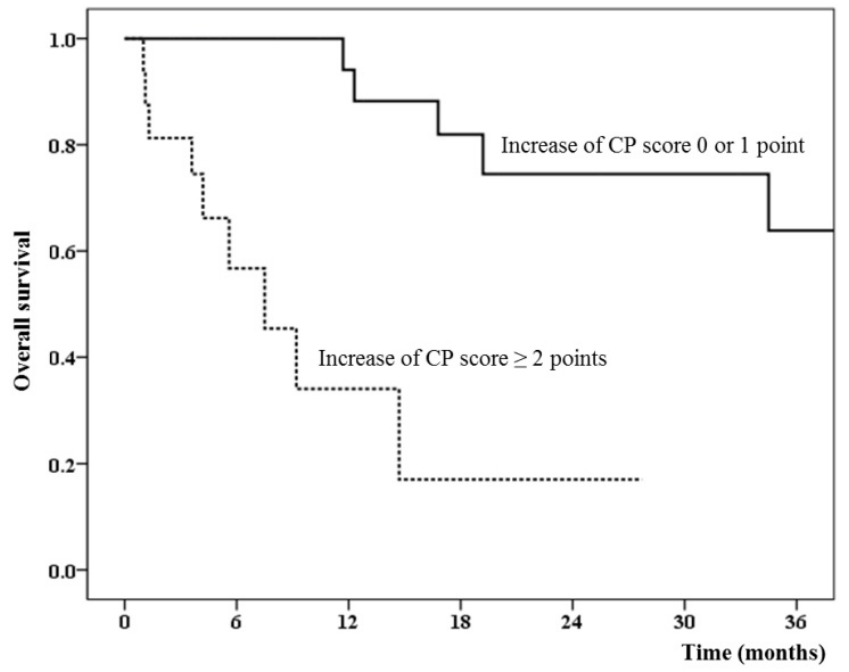

Figure 1. The overall survival difference between patients who had radiation-induced hepatic toxicity defined by the increase in Child-Pugh score of 2 points or more.

The change in $\mathrm{CP}$ score of 1 point or 3 points or the change in the $\mathrm{CP}$ class (from $\mathrm{A}$ to $\mathrm{B}$ or $\mathrm{C}$, or from $\mathrm{B}$ to $C)$ also showed similar results as those for the change in CP score of 2 points; however, statistical significance was lower based on our hypothesis.

\section{Discussion}

Recent studies of RT in HCC patients showed that non-classic RILD occurred more frequently than classic RILD [5, 18]. However, there is no clear definition or criteria of non-classic RILD. In Quantitative Analyses of Normal Tissue Effects in the Clinic (QUANTEC) report, it has been suggested to use CTCAE grading system or to document the changes in $\mathrm{CP}$ score for describing this type of RILD [6]. However, the clinical significance of these criteria has not been reported.

Therefore, although several studies of the clinical and toxicity outcome of liver SBRT have been reported, the inclusion criteria as well as the definition of RIHT varied among studies. Janoray et al. included 23 HCC and 41 metastatic liver cancer patients [8]. Two dose schemes of $45 \mathrm{~Gy}$ or $60 \mathrm{~Gy}$ in 3 fractions were used. They defined RIHT as a triad of ascites, hepatomegaly, and a grade 3 or higher elevation of liver enzymes according to the CTCAE. The rate of RIHT was $9 \%$ if the elevation of gamma-glutamyl transpeptidase (GGT) was included, or the rate of RIHT was $0 \%$ if the elevation of GGT was not included. In our study, GGT was not included in the analysis because the GGT level was available in only $3(6.7 \%)$ patients.

Tse et al. reported the phase I study results of SBRT in 41 patients with HCC or intrahepatic cholangiocarcinoma [19]. They defined dose limiting toxicity as CTCAE grade 4 or higher toxicity or the development of classic RILD which requires treatment. No dose limiting toxicity was observed when the median dose was 36.0 Gy in 6 fractions.

Andolino et al. treated 60 primary HCC patients with SBRT which was delivered with a median dose of 44 Gy in 3 fractions [7]. The toxicity profile was reported according to the CTCAE and the change in CP class. AST, ALT, BIL, ALB, INR, and hematologic laboratory findings were used for the CTCAE. There were $21(35.0 \%)$ patients with grade 3 hematologic or hepatic toxicity. Of these patients, 17 patients already had pre-existing grade 2 dysfunction, and 8 (13\%) patients had an increase in hematologic/hepatic dysfunction greater than one grade. They also reported the rate of change in $\mathrm{CP}$ class as $20 \%$. They reported that the pre-treatment $\mathrm{CP}$ score was important for predicting RIHT.

Jung et al. included 92 HCC patients who received SBRT which was delivered with a median dose of 45 Gy [11]. They defined RIHT as grade 2 or higher hepatic toxicity according to the CTCAE and/or non-malignant ascites. They included AST, ALT, ALP and BIL for analysis and excluded the patients who had disease progression within 3 months. The reported rate of RIHT was $18.5 \%$.

As shown above, variable definitions of RIHT were used in liver SBRT. Not only the criteria but also the reported cut-off grade, and included parameters varied among studies. Therefore, we performed the present study to evaluate which criteria and parameters were clinically meaningful to define RIHT in HCC patients.

In our study, the grade 2 or higher increase in serum transaminases (AST, ALT) showed no correlation with the mean liver dose and survival. These parameters could also be affected by other local treatments such as TACE. Therefore, inclusion of these parameters in the definition of RIHT seems to over-estimate the rate of RIHT. The increase in ALP was rare, and it was observed in only one patient $(2.2 \%)$. This patient received a relatively high mean liver dose (22.8 Gy), but it was difficult to consider it as RIHT. BIL, ALB, and INR, which are the parameters included in the $\mathrm{CP}$ score, showed some correlation with the development of liver failure and death. Overall, compared to the CTCAE, the increase in $\mathrm{CP}$ score showed a better correlation with the mean liver dose, the development of liver failure, and overall survival. It was also not affected by other local treatments or disease progression. The best cut-off point for the $\mathrm{CP}$ score was 2 points, at which the survival difference was maximum. None of the 29 patients whose $\mathrm{CP}$ score was not increased by more 
than 2 points within 3 months after SBRT developed liver failure at the last follow-up.

The CTCAE $\geq$ grade 2 or change in CP class could also be a criterion for RIHT, although it seems that these criteria could over-estimate the rate of RIHT. In our study, the rate of RIHT was $35.5 \%$ when the criterion was the increase in $\mathrm{CP}$ score $\geq 2$ points, $62.2 \%$ for CTCAE $\geq$ grade $2,48.8 \%$ for change in CP class. The reasons for the high rate of RIHT in our study compared to other studies were as follows; 1 ) high proportion of patients who had underlying liver cirrhosis, 2) a relatively larger target volume compared to other studies, and 3) non-exclusion of the patients who had intrahepatic progression.

If patients who experienced intrahepatic tumor progression were excluded from the analysis of RIHT such as in other studies, the rate of RIHT could be under-estimated, because not all patients who had intrahepatic disease progression developed decline in liver function. From our study results, it seems that it is not essential to exclude patients with intrahepatic tumor progression for counting the RIHT if the increase in $\mathrm{CP}$ score of 2 points was used as the criterion for RIHT.

The reporting method of $\mathrm{CP}$ score is also more convenient than the CTCAE. Since the liver function is already decreased before RT in some HCC patients, reporting the pre- and post-RT CTCAE grade for each parameter is very complicate. However, with respect to the $\mathrm{CP}$ score, reporting only two digits of pre- and post-RT CP scores is sufficient.

From our study results, we could not suggest that reporting the $\mathrm{CP}$ score is sufficient or an increase in $\mathrm{CP}$ score of 2 points should be the definition of non-classic RILD. The number of patients in our study was not sufficient to acquire enough statistical power. A validation study was also not performed. The retrospective nature of this study may have also caused selection bias. In addition, the hepatitis B virus reactivation rate, which can also be an important confounding factor, was not assessed in this study because of insufficient data for viral copies. However, at least, reporting the pre- and post-RT CP scores and assessing the proportion of patients whose $\mathrm{CP}$ score was increased by $\geq 2$ points seems to be essential in liver SBRT studies, especially in HCC patients with underlying chronic liver disease.

\section{Conclusion}

In conclusion, in HCC patients treated with liver SBRT, RIHT was better defined by the change in CP score rather than the CTCAE. The increase in CP score of 2 points or more was more correlated with liver failure and overall survival, and it was not affected by other local treatments or disease progression.

\section{Abbreviations}

HCC: Hepatocellular carcinoma; RT: Radiation Therapy; RIHT: Radiation-induced hepatic toxicity; RILD: Radiation-induced liver disease; CTCAE: Common Terminology Criteria for Adverse Events; CP: Child-Pugh; TACE: trans-arterial chemoembolization; SBRT: stereotactic body radiotherapy; AST: aspartate transaminase; ALT: alanine transaminase; ALP: alkaline phosphatase; BIL: total bilirubin; ALB: albumin; INR: international normalized ratio for the prothrombin time.

\section{Competing Interests}

The authors have declared that no competing interest exists.

\section{References}

1. Jung KW, Won YJ, Kong HJ, et al. Cancer statistics in Korea: incidence, mortality, survival, and prevalence in 2012. Cancer Res Treat. 2015; 47: 127-41.

2. 2014 Korean Liver Cancer Study Group-National Cancer Center Korea. Practice Guideline for the Management of Hepatocellular Carcinoma. Korean J Radiol. 2015; 16: 465-522

3. EASL-EORTC clinical practice guidelines: management of hepatocellular carcinoma. J Hepatol. 2012; 56: 908-43.

4. Kalogeridi MA, Zygogianni A, Kyrgias G, et al. Role of radiotherapy in the management of hepatocellular carcinoma: A systematic review. World J Hepatol. 2015; 7: 101-12.

5. Guha C, Kavanagh BD. Hepatic radiation toxicity: avoidance and amelioration. Semin Radiat Oncol. 2011; 21: 256-63.

6. Pan C, Kavanagh B, Dawson L, et al. Radiation-associated liver injury. Int J Radiat Oncol Biol Phys. 2010; 76: S94-100.

7. Andolino DL, Johnson CS, Maluccio M, et al. Stereotactic Body Radiotherapy for Primary Hepatocellular Carcinoma. Int J Radiat Oncol Biol Phys. 2011; 81: e447-e53.

8. Janoray G, Chapet $S$, Ruffier-Loubière A, et al. Robotic stereotactic body radiation therapy for tumours of the liver: Radiation-induced liver disease, incidence and predictive factors. Cancer Radiother. 2014; 18: 191-7.

9. Kwon JH, Bae SH, Kim JY, et al. Long-term effect of stereotactic body radiation therapy for primary hepatocellular carcinoma ineligible for local ablation therapy or surgical resection. Stereotactic radiotherapy for liver cancer. BMC Cancer. 2010; 10: 475.

10. Son SH, Choi BO, Ryu MR, et al. Stereotactic Body Radiotherapy for Patients With Unresectable Primary Hepatocellular Carcinoma: Dose-Volumetric Parameters Predicting the Hepatic Complication. Int J Radiat Oncol Biol Phys. 2010; 78: 1073-80.

11. Jung J, Yoon SM, Kim SY, et al. Radiation-induced liver disease after stereotactic body radiotherapy for small hepatocellular carcinoma: clinical and dose-volumetric parameters. Radiat Oncol. 2013; 8: 249.

12. Kim YI, Park HC, Lim do H, et al. Changes of the liver volume and the Child-Pugh score after high dose hypofractionated radiotherapy in patients with small hepatocellular carcinoma. Radiat Oncol J. 2012; 30: 189-96.

13. Long Z, Wang B, Tao D, et al. Clinical research on alternating hyperfraction radiotherapy for massive hepatocellular carcinoma. Oncol Lett. 2015; 10: 523-7.

14. Meng MB, Cui YL, Lu Y, et al. Transcatheter arterial chemoembolization in combination with radiotherapy for unresectable hepatocellular carcinoma: a systematic review and meta-analysis. Radiother Oncol. 2009; 92: 184-94.

15. Kim SW, Oh D, Park HC, et al. Transcatheter arterial chemoembolization and radiation therapy for treatment-naive patients with locally advanced hepatocellular carcinoma. Radiat Oncol J. 2014; 32: 14-22.

16. Cox JD, Stetz J, Pajak TF. Toxicity criteria of the Radiation Therapy Oncology Group (RTOG) and the European Organization for Research and Treatment of Cancer (EORTC). Int J Radiat Oncol Biol Phys. 1995; 31: 1341-6.

17. Cholongitas E, Papatheodoridis GV, Vangeli M, et al. Systematic review: the model for end-stage liver disease - should it replace Child-Pugh's classification for assessing prognosis in cirrhosis? Aliment Pharmacol Ther. 2005; 22: 1079-89.

18. Sanuki N, Takeda A, Kunieda E. Role of stereotactic body radiation therapy for hepatocellular carcinoma. World J Gastroenterol. 2014; 20: 3100-11.

19. Tse RV, Hawkins M, Lockwood G, et al. Phase I study of individualized stereotactic body radiotherapy for hepatocellular carcinoma and intrahepatic cholangiocarcinoma. J Clin Oncol. 2008; 26: 657-64. 